\title{
SDS-Page Seed Storage Protein Profiles in Chili Peppers (Capsicum L.)
}

\author{
Owk ANIEL KUMAR, Sape SUBBA TATA \\ AndhraUniversity,_Department of Botany,Visakhapatnam,India; s_tata_s@yahoo.co.in,owkanielkumar@yahoo.com
}

\begin{abstract}
Seed protein banding patterns (SDS-PAGE) were studied from eighteen genotypes of chili pepper (Capsicum L). A total of 21 protein polypeptide bands with molecular weight ranging from 18.6 to $72.0 \mathrm{kD}$ were recorded. Among the genotypes 'CA18', 'CA21' and 'CA27' represented maximum number of protein bands (12). Band no. (11) and $(5,12)$ are exclusive to $C$. annuum L. and $C$. frutescens L. genotypes respectively. Average percent similarity was highest (100\%) between 'CA2' and 'CA8' genotypes and the UPGMA dendrogram represented low genetic diversity. The study revealed that considerable intra and inter-specific differences were found in the genotypes. The variability of protein profiles in the genotypes suggested that these selected genotypes can be a good source for crop improvement through hybridization programs.
\end{abstract}

Keywords: Capsicum, SDS-PAGE, similarity index, UPGMA

\section{Introduction}

Chili peppers (Capsicum L.) are the most important vegetable cum spice because of their colour, taste, pungency, flavor and aroma belongings to the family Solanaceae grown in tropical and sub tropical regions of the world. Members of the genus are diploids $(2 n=24)$ and are either annuals or perennials. Moreover, most of the varieties or cultivars within a species show resemblance with their morphometrics. The data on agronomic, morphological and physiological plant traits are generally used to estimate the magnitude of genetic diversity present in the germplasm. However, such data may not provide an accurate indication of genetic diversity because of environmental influences upon the expression of observed traits. Moreover, field evaluation of plant material is often laborious and time consuming especially, when a large number of accessions are to be analyzed. Considering these difficulties the introduction of biochemical techniques has made possible and a more accurate evaluation of genetic variation, bringing greater precision to measures of genetic diversity. Among the biochemical techniques, Sodium dodecyl sulphate polyacrylamide gel electrophoresis (SDS-PAGE) is an economical, simple and extensively used biochemical technique for describing the seed protein diversity of crop germplasm (Cook, 1995; Das and Mukarjee, 1995; Fufa et al., 2005; Iqbal et al., 2005). Furthermore, seed proteins used as genetic markers in the study of genetic variation because they are the primary products of structural genes, any change in the coding sequence of a gene generally reflects the corresponding change in the primary structure of protein (Srivalli et al., 1999). Genetic and taxonomic relationships in the genus Capsicum have been investigated with electrophoresis of seed storage protein banding patterns
(Panda et al., 1986; Vladova and Pandeva, 1994; Vladova et al., 2000; Vladova et al., 2004; Zubaida et al., 2006). Genotypic variations of seed protein profiles in chili peppers have been reviewed by Lucchese et al. (1999), Posch et al. (1994), Srivalli et al. (1999), Vladova et al. (2000). However, polymorphism of seed storage protein profiles in Capsicum annuum L. and Capsicum frutescens L. germplasm has been associated with geographical origin (Anu and Peter, 2003; Odeigah et al., 1999). Despite many reports of SDS-PAGE seed storage protein profiles in chili pepper is inadequate. Therefore the present study is under taken to evaluate the seed protein variability in eighteen genotypes of chili peppers (Capsicum L.) for their exploitation in successful crossing programs.

\section{Materials and methods}

\section{Seed material}

Seventeen genotypes of Capsicum annuum L. were denoted by these numbers i.e., ('CA1', 'CA2', 'CA3', 'CA4', 'CA5', 'CA8', 'CA10', 'CA13, 'CA16, 'CA17', 'CA18, 'CA19', 'CA20', 'CA21', 'CA22,' 'CA25' and 'CA27') and one genotype of Capsicum frutescens $\mathrm{L}$ ('CF') were obtained from Sutton and Seeds, Calcutta, India. They were grown in randomized design with three replicates at the experimental farm of Andhra University, Visakhapatnam, which allowed production under the same cultivation conditions to obtain seeds with the same physiological quality. They were harvested manually and dried in the sun light.

\section{Seed protein extraction}

About 200mg seeds from each genotype homogenized with the help of mortar and pestle using $0.01 \mathrm{M}$ Tris-Hcl 
buffer ( $\mathrm{pH} 7.5)$. The resulting homogenates were centrifuged at $15000 \mathrm{rpm}$ for 10 minutes then the supernatants were filtered with 541 Whatmann filter paper and the obtained residues were boiled at $90^{\circ} \mathrm{C}$ for five minutes with $1: 1$ ratio of $1.0 \mathrm{M}$ Tris ( $\mathrm{pH} 6.8$ ), $10 \%$ SDS, $2 \%$ $\beta$-mercaptoethanol, 10\% glycerol and $0.002 \%$ bromophenol blue.

\section{$S D S-P A G E$}

Extracted soluble proteins were fractionated by one dimensional SDS-PAGE (Laemmli, 1970). Ten and five percent running and stacking gels were used, gels measured $(18 \mathrm{cmX} 16 \mathrm{cmX} 0.1 \mathrm{~cm})$. Electrophoresis was conducted at a constant current $35 \mathrm{~mA}$ until the tracking dye reached the bottom of the gel. After electrophoresis, the gels were stained overnight in $0.25 \%$ Coomassie brilliant blueR250, followed by de-staining in methanol and acetic acid for 45 minutes. The gels were further de-stained until the back ground was clear enough for bands scoring. Marker proteins (RPMW) were used as references. Molecular weights of protein bands were estimated by their relative mobilities. In order to eliminate differences in electrophoretic conditions as a cause of variation in the protein profiles, each genotype protein sample was separated from three independent electrophoretic runs and two separate extractions.

\section{Data analysis}

The gels were scored as presence $(+)$ or absence $(-)$ of protein polypeptide bands and their staining intensities i.e., faint, medium and intensed. Depending upon the presence or absence of polypeptide bands, similarity index (SI) (Nei and Li, 1979) between the genotypes was calculated by the following formula:

$$
S I=\frac{2 Z}{X+Y} \times 100
$$

Where, $Z=$ Number of similar bands between the genotypes and $\mathrm{X}+\mathrm{Y}=$ Total number of bands in the two genotypes compared. Cluster analysis UPGMA (Unweighted pair group method with arithmetic averages) was performed on the similarity index by using statistical software SPSS for windows package (Version 10).

\section{Results and discussions}

Protein distribution patterns in eighteen genotypes of chili peppers (Capsicum L.) were studied and reveal qualitative and quantitative intra and interspesific variations in terms of band number, staining intensity and molecular weight (Tab. 1 and Fig. 1). Twenty one protein polypeptide bands of diverse molecular weights ranging from 18.6 to $72.0 \mathrm{kD}$ were identified, three were monomorphic. The

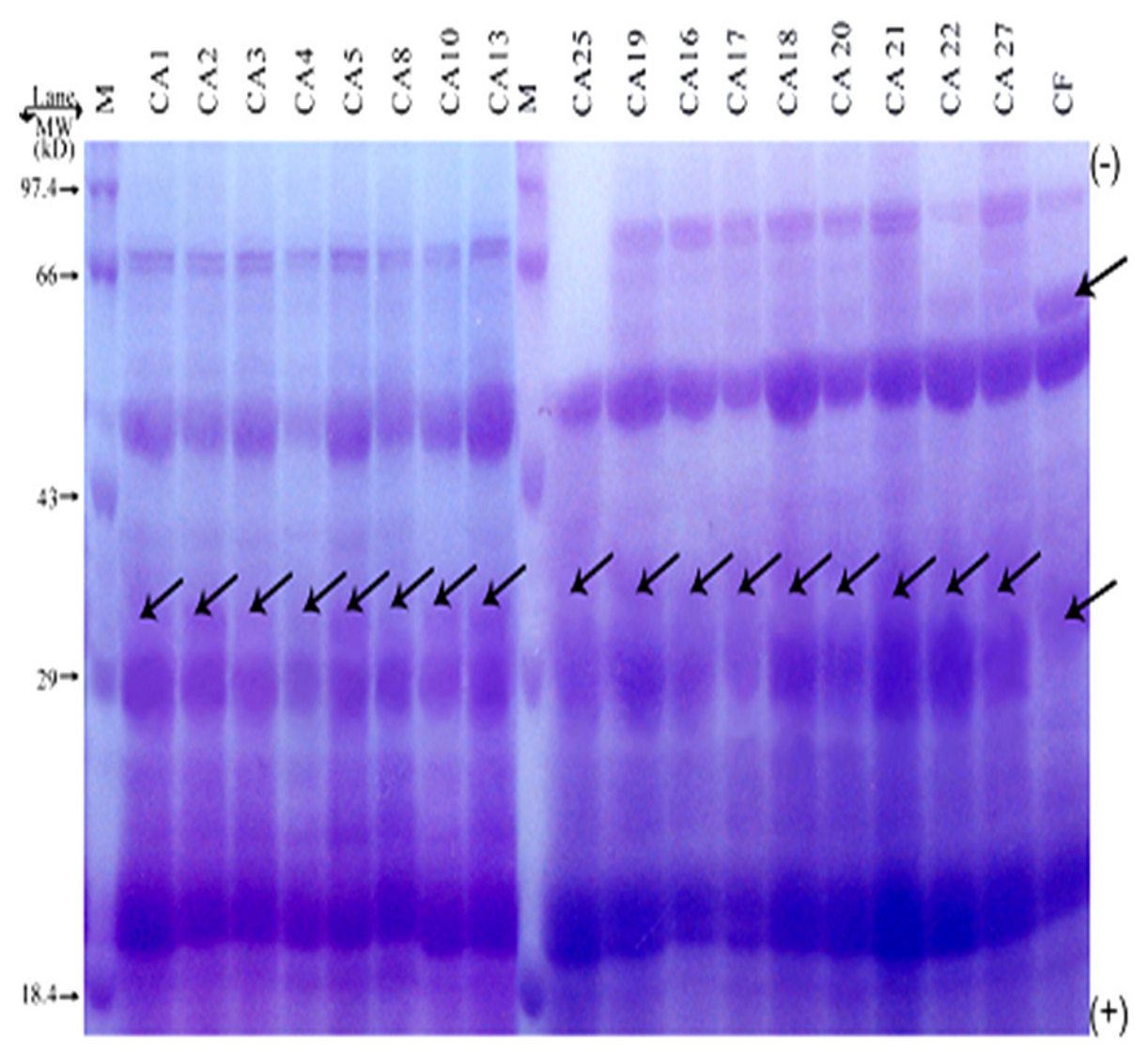

Fig. 1. Seed storage protein profiles in eighteen genotypes of chili pepper (Capsicum L.) on 10\% SDS polyacrylamide gel. Arrows represent the species specific bands 

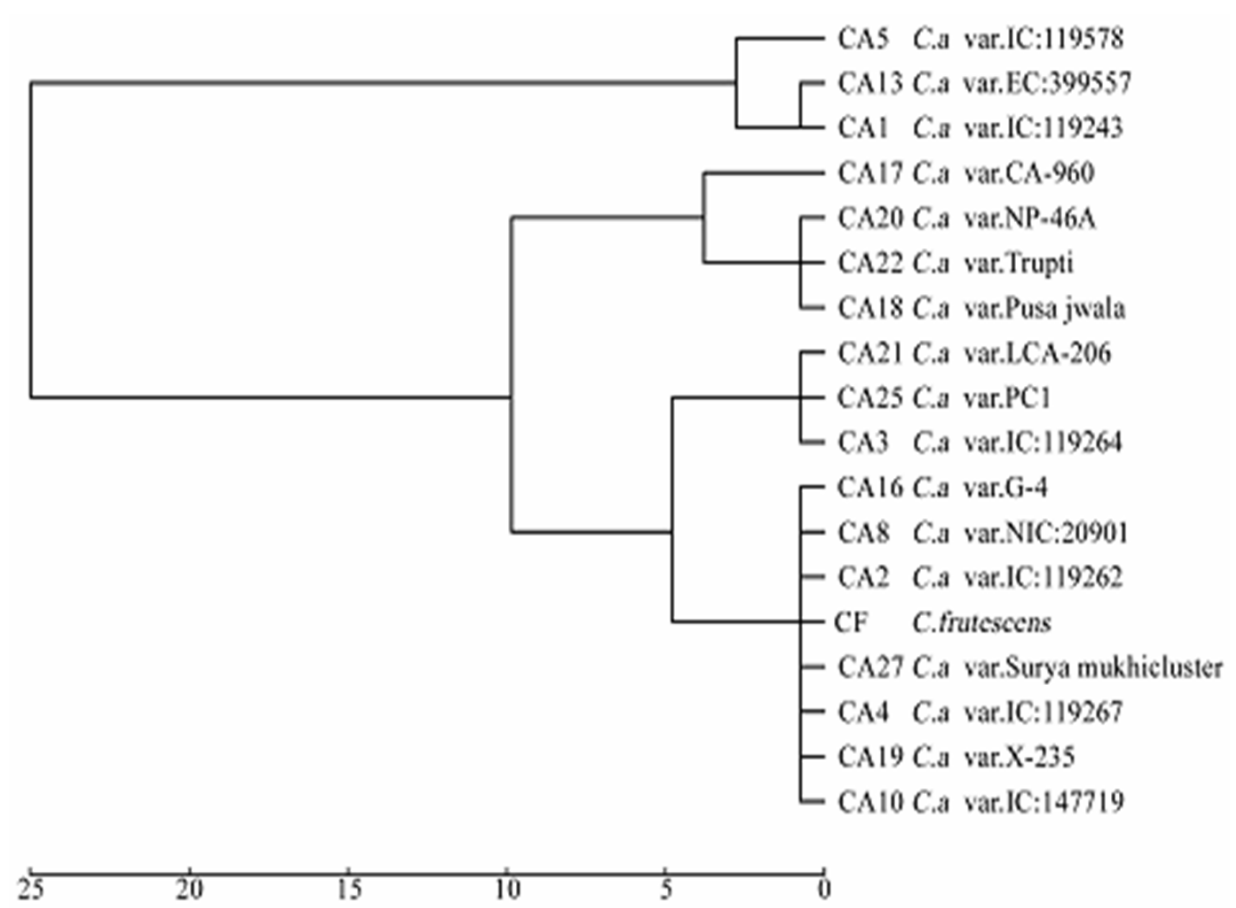

\section{SIMILARITY}

Fig. 2. UPGMA dendrogram of eighteen genotypes of chili pepper (Capsicum L.) based on seed storage protein profiles

genotypes showed considerable variation in protein band number ranged from 8-12 in agreement with previous observations in chili peppers (Lucchese et al., 1999; Odeigah et al., 1999; Posch et al., 1994; Srivalli et al., 1999). Among the genotypes 'CA18', 'CA21' and 'CA27' showed maximum (12) resolved protein bands while, the minimum (8) were recorded in 'CA16' and 'CA25' genotypes respectively. Band no.16(23.6kD), 17(22.0kD) and $21(18.6 \mathrm{kD})$ were common in all the genotypes whereas band no. $1(72.0 \mathrm{kD})$ was missing in genotype 'CA25'. However, band no.11 was recorded in genotypes of Capsicum annu$u m \mathrm{~L}$. whereas band no. 5 and 12 were present in genotype Capsicum frutescens $\mathrm{L}$. and these bands can be considered as species specific (Fig. 1). Similar results were obtained by Odeigah et al. (1999) in cultivars of $C$. annuum L. and $C$. frutescens $\mathrm{L}$. Based on molecular weights the banding pattern revealed three regions viz., Region I ( $0-25.0 \mathrm{kD})$ comprised 6 bands, Region II (25.1-50.0kD) consisted of 10 bands, while Region III (50.1-75.0kD) had 5 bands. Most of the protein bands were faint and intensed in staining. The results are in conformity with the findings of Anu and Peter (2003); Panda et al. (1986); Vladova and Pandeva (1994); Zubaida et al. (2006). Similarity index for eighteen genotypes ranged from 42.10 to $100 \%$. Highest percent similarity was recorded between 'CA2' and 'CA8' (100\%) while, the minimum between 'CA19' and 'CF' (42.10\%). Such higher percent similarities were also reported in cultivars of $C$. annuum L. by Anu and Peter (2003). Cluster analysis of banding pattern of examined genotypes based on similarity index and UPGMA resulted four distinct clusters (Fig. 2). Cluster 1 consisted of 8 genotypes, cluster 2 comprised of 3 genotypes, cluster 3 had 3 genotypes and cluster 4 manifested 2 genotypes. The dendrogram as a whole revealed low genetic diversity because most of the varieties are in the same cluster. Fufa et al. (2005) reported that the genetic diversity estimates based on seed storage protein were lowest because they were the major determinants of the end-use quality, which is a highly selected trait. Large intra and inter specific differences were not found in genotypes of chili pepper (Capsicum $\mathrm{L})$, this may be due to genotype homogeneity or purity (Odeigah et al., 1999). Our results suggest that five genotypes i.e., 'CA4', 'CA10', 'CA16, 'CA25' and 'CF' showed better demarked protein profiles with reference to their band presence or absence, intensity and molecular weights can be recommended in breeding programs to develop chili pepper varieties.

\section{Conclusions}

Electrophoresis (SDS-PAGE) of seed storage proteins can be economically used to assess genetic diversity in germplasm. The study revealed that considerable intra and inter-specific variations were found in the genotypes however, band no. 11 (Capsicum annuum L.), 5 and 12 (Capsicum frutescens L.) can be identified as species specific. Based on the resolved protein profiles five genotypes i.e., 'CA4', 'CA10', 'CA16,' 'CA25' and 'CF' represented better demarked protein banding patterns can be suggested for future breeding programs. 
Tab.1. Rm values, molecular weights and band presence or absence in eighteen genotypes of chili pepper (Capsicum L.)

\begin{tabular}{|c|c|c|c|c|c|c|c|c|c|c|c|c|c|c|c|c|c|c|c|c|}
\hline \multirow{3}{*}{$\begin{array}{c}\text { Band } \\
\text { No. }\end{array}$} & \multirow{3}{*}{$\begin{array}{c}\mathrm{Rm} \\
\text { value }\end{array}$} & \multirow{3}{*}{$\begin{array}{c}\text { Molecular } \\
\text { weight } \\
(\mathrm{kD})\end{array}$} & \multicolumn{18}{|c|}{ Band presence $(+) /$ absence(-) } \\
\hline & & & \multicolumn{18}{|c|}{ Genotypes } \\
\hline & & & 'CA1' & 'CA2' & 'CA3' & 'CA4' & 'CA5' & 'CA8' & 'CA10' & 'CA13' & 'CA16' & 'CA17’ & 'CA18' & 'CA19' & 'CA20' & 'CA21' & 'CA22' & 'CA25’ & ‘CA27’ & 'CF' \\
\hline 1 & 0.230 & 72.0 & + & + & + & + & + & + & + & + & + & + & + & + & + & + & + & - & + & + \\
\hline 2 & 0.269 & 63.2 & - & - & - & - & - & - & - & - & - & + & + & + & + & + & - & - & + & - \\
\hline 3 & 0.276 & 62.4 & + & + & + & + & + & + & + & + & - & - & - & - & - & - & - & - & - & - \\
\hline 4 & 0.323 & 56.8 & - & - & - & - & - & - & - & - & - & + & + & + & + & + & + & - & + & - \\
\hline 5 & 0.346 & 54.4 & + & + & + & - & + & + & - & + & - & - & - & - & - & - & - & - & - & + \\
\hline 6 & 0.400 & 48.8 & - & + & - & + & - & + & + & - & - & + & - & - & + & - & - & - & - & - \\
\hline 7 & 0.415 & 47.2 & + & - & + & - & + & - & - & + & + & - & - & - & - & + & - & + & + & + \\
\hline 8 & 0.430 & 46.0 & - & - & - & - & - & - & - & - & - & - & + & + & - & - & + & - & - & - \\
\hline 9 & 0.453 & 44.0 & - & - & - & - & - & - & - & - & - & - & + & - & - & + & - & - & + & - \\
\hline 10 & 0.500 & 40.0 & + & + & + & + & + & + & - & + & - & - & + & - & + & + & - & + & + & + \\
\hline 11 & 0.576 & 33.6 & + & + & + & + & + & + & + & + & + & + & + & + & + & + & + & + & + & - \\
\hline 12 & 0.623 & 30.0 & - & - & - & - & - & - & - & - & - & - & - & - & - & - & - & - & - & + \\
\hline 13 & 0.646 & 28.4 & - & - & - & + & - & - & - & - & - & - & - & - & - & - & - & - & - & - \\
\hline 14 & 0.661 & 27.2 & - & + & + & - & - & + & + & - & - & + & - & - & + & - & - & - & - & - \\
\hline 15 & 0.676 & 26.4 & + & - & - & - & + & - & - & + & + & - & + & + & - & + & + & + & + & - \\
\hline 16 & 0.730 & 23.6 & + & + & + & + & + & + & + & + & + & + & + & + & + & + & + & + & + & + \\
\hline 17 & 0.769 & 22.0 & + & + & + & + & + & + & + & + & + & + & + & + & + & + & + & + & + & + \\
\hline 18 & 0.823 & 20.0 & - & + & + & - & - & + & - & - & + & + & - & - & - & - & - & - & - & + \\
\hline 19 & 0.830 & 19.6 & - & - & - & + & + & - & - & - & - & - & + & - & + & - & + & - & + & - \\
\hline 20 & 0.838 & 19.4 & + & - & - & - & - & - & + & + & - & - & - & + & - & + & - & + & - & - \\
\hline 21 & 0.876 & 18.6 & + & + & + & + & + & + & + & + & + & + & + & + & + & + & + & + & + & + \\
\hline \multicolumn{3}{|c|}{ Total number of bands } & 11 & 11 & 11 & 10 & 11 & 11 & 9 & 11 & 8 & 10 & 12 & 10 & 11 & 12 & 9 & 8 & 12 & 9 \\
\hline
\end{tabular}


90

\section{Acknowledgements}

One of the authors (O. Aniel Kumar) is grateful to UGC-SAP, Department of Botany, Andhra University, Visakhapatnam for providing financial assistance.

\section{References}

Anu, A. and K. V. Peter (2003). Analysis of seed protein of 29 lines of Capsicum annum L. by polyacrylamide gel electrophoresis. Genetic Resources and Crop Evolution 50:239-243.

Cook, R. J. (1995). Gel electrophoresis for the identification of plant varieties. J. Chromatogr 698:281-299.

Das, S. and K. K. Mukarjee (1995). Comparative study on seed proteins of Ipomea. Seed Science and Technology 23:501509.

Fufa, H., P. S. Baenziger., B. S. Beecher., I. Dweikat., R. A. Graybosch and K. M. Eskridge (2005). Comparison of phenotypic and molecular marker based classifications of hard red winter wheat cultivars. Euphytica 145:133-146.

Iqbal, S. H., A. Ghafoor and N. Ayub (2005). Relationship between SDS-PAGE markers and Ascochyta blight in chickpea. Pakistan Journal of Botany 37:87-96.

Laemmli, U. K. (1970). Cleavage of structural proteins during the assembly of the head of bacteriophage T4. Nature 227:680-685.

Lucchese, C., G. Dinelli, A. Miggiano and A. Lovato (1999). Identification of pepper (Capsicum spp.) cultivars by field and electrophoresis tests. Seed Sci. and Tech. 27:37-47.

Nei, M. and W. H. Li (1979). Mathematical model for studying genetic variation in terms of restriction endonucleases. Proc. Natl. Acad. Sci. USA. 76:127-5273.

Odeigah, P. G. C., B. Oboh and I. O. Aghalokpe (1999). The characterization of Nigerian varieties of pepper, Capsicum annuum and Capsicum frutescens by SDS-polyacrylamide gel electrophoresis of seed proteins. Genetic Resources and Crop Evolution 46:127-131.
Panda, R. C., O. Aniel Kumar and K. G. Raja Rao (1986). The use of seed protein electrophoresis in the study of phylogenetic relationships in chilli pepper (Capsicum L.). Theoretical and Applied Genetics 72:665-670.

Posch, A., B. M. Vanderberg, C. Duranton and A. Gorg (1994). Polymorphism of pepper (Capsicum annuum L.) seed proteins studied by two-dimensional electrophoresis with immobilized pHgradients. Methodical and genetics aspects. Electrophoresis 15:297-304.

Srivalli, T., N. Lakshmi and C. H. G. Gupta (1999). Analysis of seed proteins by polyacylamide gel electrophoresis (PAGE) in diploids, tetraploids and tetraploid hybrids of Capsicum. Capsicum and Eggplant Newsletter 18:48-51.

Vladova, R. and R. Pandeva (1994). Electrophoretic profiles of seed proteins in the genus Capsicum. Capsicum and Eggplant Newsletter 13:81-84.

Vladova, R., K. Petcolicheva., R. Pandeva and V. Nikova (2000). Seed storage proteins of Capsicum annuиm L., Nicotiana tabaccum L. and Lycopersicon esculentum L. cultivars: comparative electrophoretic study. Plant genetic and breeding 30:29-33.

Vladova, R., R. Pandeva and K. Petcolicheva (2000). Seed storage proteins in Capsicum annuum cultivars. Biologia Plantarum 43(2):291-295.

Vladova, R., V. Tsanev and K. Petcolicheva (2004). Seed storage proteins in Solanaceae and Cucurbitaceae species. Biologia Plantarum 48(4):601-603

Zubaida, Y., M. Shahib., S. K Zabta., K. Mir Ajab and R. Ashiq (2006). Evaluation of taxonomic status of medicinal species of the genus Solanum and Capsicum based on polyacrylamide gel electrophoresis. Pakistan Journal of Botany 38(1):99106. 